\title{
A Compact Tri-Band Antenna Based on Inverted-L Stubs for Smart Devices
}

\author{
Niamat Hussain ${ }^{1}$, Anees Abbas ${ }^{1}$, Sang-Myeong Park ${ }^{1}$, Seong Gyoon Park ${ }^{2}$ and Nam Kim ${ }^{1, *}$ \\ ${ }^{1}$ Department of Information and Communication Engineering, Chungbuk National University, Cheongju, 28644, Korea \\ ${ }^{2}$ Department of Information and Communication Engineering, Kongju National University, Kongju, 32588, Korea \\ *Corresponding Author: Nam Kim. Email: namkim@chungbuk.ac.kr \\ Received: 02 June 2021; Accepted: 03 July 2021
}

\begin{abstract}
We designed and constructed a novel, compact tri-band monopole antenna for intelligent devices. Multiband behavior was achieved by placing inverted-L shaped stubs of various lengths in a triangular monopole antenna fed by a coplanar waveguide. The resonance frequency of each band can be controlled by varying the length of the corresponding stub. Three bands, at 2.4 (2.37-2.51), 3.5 (3.34-3.71), and 5.5 (4.6-6.4) GHz, were easily obtained using three stubs of different lengths. For miniaturization, a portion of the longest stub (at $2.4 \mathrm{GHz}$ ) was printed on the opposite side of the substrate, and connected to the main stub via a shorting pin. To validate the concept, the antenna was fabricated on a low-cost 1.6-mm-thick FR-4 substrate with dimensions of $20 \times 15 \times 1.6 \mathrm{~mm}^{3}$. The antenna exhibited a moderate average gain of $2.9 \mathrm{dBi}$ with an omnidirectional radiations over the bandwidths required for RFID, Bluetooth, ISM, WiMAX, and WLAN-band applications. These features make the antenna suitable for compact smart devices.
\end{abstract}

Keywords: Multiband antenna; compact antenna; tri-band antenna; CPW antenna; stub-loaded antenna

\section{Introduction}

The need for multiband, planar, low-profile compact antennas has increased given the incorporation of multiple communications systems within a single electronic device. The systems operate at various frequencies ranging from 2 to $7 \mathrm{GHz}$. Popular frequency bands include the Industrial Scientific and Medical (ISM-2.4 GHz), Bluetooth $(2.4 \mathrm{GHz}$ ), and long term evolution (LTE-2.5) bands, the $5 \mathrm{G}$ sub- $6 \mathrm{GHz}$ band $(3.5 \mathrm{GHz}$ ), and the radio frequency identification (RFID-2.54/5.8 $\mathrm{GHz}$ ) and wireless local area network (WLAN-2.4/5.2/5.8 GHz) bands. No single antenna can operate in all of these frequency bands; multiple antennas are required. However, the devices must be compact and inexpensive. Therefore, multiband antennas are essential [1].

Printed antennas are cheap, easy to design, have multiband functionality, and are readily integrated with other circuits. Many printed multiband antennas have been developed [2-30]. In [2-7], slots of various shapes were created in a radiator and excited various operating bands. The resonance frequency was controlled by varying the electrical length of the slots. Some studies used asymmetric coplanar strip (ACS)-fed meander lines to ensure multiband operation, while

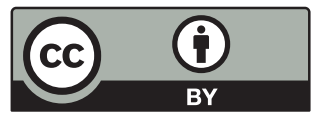

This work is licensed under a Creative Commons Attribution 4.0 International License, which permits unrestricted use, distribution, and reproduction in any medium, provided the original work is properly cited. 
avoiding the need for complex antenna geometries [8,9]. Defected ground structures (DGS) [10,11], stacked layers [12,13], parasitic elements [14,15], and metamaterials have also been employed to create multiband antennas [16-20].

Many tri-band antennas operating in major frequency bands have been used to satisfy bandwidth requirements, and ensure stable gain, high radiation efficiency, and omnidirectional radiation reception [21-30]. A compact tri-band antenna with multiple metallic strips in a dual F-shaped monopole was presented in [21]. This antenna operates in the 1.9, 3.5, and 5.5 GHz bands and has good radiation characteristics. Another tri-band antenna, resonating at 2.4, 3.5, and $5.5 \mathrm{GHz}$ and exhibiting omnidirectional radiation patterns, was proposed in [22]: a truncated rectangular patch, $\pi$-shaped slot, and inverted-L slot were used to achieve the required resonance. The antenna has a high radiation efficiency (flat gain of $3.39 \mathrm{dBi}$ ).

A uniplanar, ACS-fed tri-band antenna with extended rectangular strips was designed for portable system applications [23]. The antenna has a modified mouse and rectangular radiating strips; three different bands can operate simultaneously. Another ACS-fed F-shaped monopole with a rectangular split-ring resonator for tri-band operation was proposed in [24]. Although simple, all of the antennas described above have unique merits. However, their physical size [25-30] must be reduced for use in modern, multi-functional compact devices.

Simple, miniaturized, highly efficient and inexpensive multiband antennas are required for handheld devices. Here, we present a compact coplanar waveguide-fed tri-band antenna covering several frequency bands, including those of ISM, RFID, Bluetooth, WiMAX, WLAN, and other leading standards (e.g., 5G sub-6 GHz). The antenna has good impedance matching, omnidirectional gain, and moderate bandwidth.

\section{Antenna Geometry and Design}

In this section, we discuss the geometry of the tri-band antenna, parameter optimization, and design steps. Initially, the antenna geometry is presented with the design variables, and later design procedure is explained in detail.

\subsection{Geometry of the Tri-Band Antenna}

The antenna geometry is shown in Fig. 1. Three inverted-L shaped stubs varying in length, but with the same width (w), are connected to a triangular monopole antenna fed by a 50 -ohm coplanar waveguide strip line. To minimize size, a portion of the longest stub is printed on the back of the substrate and connected to the other portion via a metallic pin. A low-cost FR-4 substrate with a dielectric constant $\left(\epsilon_{r}\right)$ of 4.4 and loss tangent $(\tan \delta)$ of 0.02 was used to print the antenna. The overall footprint of the antenna is given by $A \times W \times h$. The optimized parameters of the antenna are as follows: $A=15 ; L=20 ; h=1.6 ; w_{L}=2 ; s=1 ; w=1 ; w_{1}=13 ; w_{2}=9.8$; $w_{3}=6 ; w_{4}=5.4 ; l_{1}=6 ; l_{2}=4 ; l_{3}=2 ; l=13 ; p=7 ; w_{s}=0.5 ; w_{F}=2$; and $g_{L}=5[$ all $=\mathrm{mm}]$.

\subsection{Antenna Design Procedure}

The design process began with a simulation, performed using CST Microwave Studio (Dassault Systèmes, Vélizy-Villacoublay, France), of a triangular monopole fed by a coplanar waveguide (CPW). A CPW feed has several advantages, including a broad impedance bandwidth and simple design. The length of a monopole can be arbitrarily extracted using the following equation:

$l=\frac{c}{4 f_{o} \sqrt{\varepsilon_{e f f}}}$ 
where $c$ is the velocity of light in free space, and $f_{o}$ is the central resonating frequency which is given by:

$f_{o}=\frac{c}{\sqrt{\varepsilon_{e f f}} \lambda_{f}}$

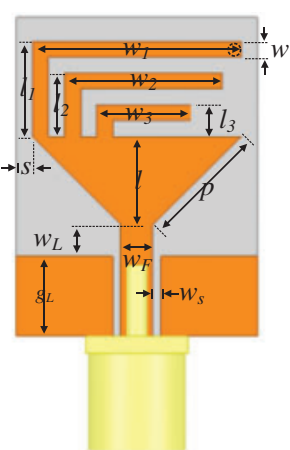

Front view

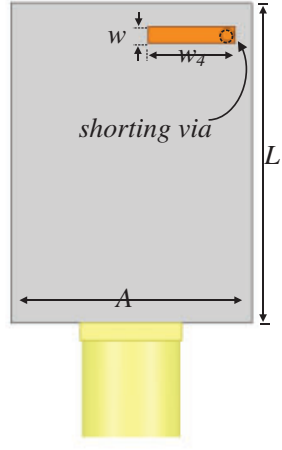

Back view

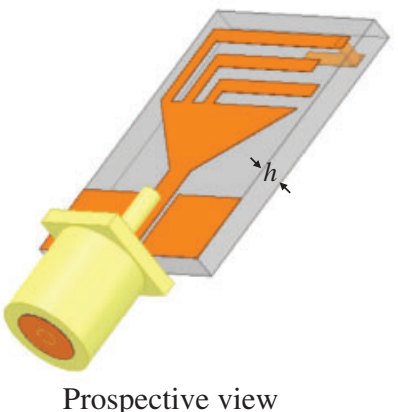

Prospective view

Figure 1: Schematics of the tri-band antenna

Here, $\quad \lambda_{f}$ is the guided wavelength at the central frequency and $\varepsilon_{\text {eff }}$ is the effective dielectric constant which is given by:

$\varepsilon_{\text {eff }} \approx \frac{\varepsilon_{r}+1}{2}+\frac{\varepsilon_{r}+1}{2}\left(1+12\left(\frac{p}{h}\right)\right)^{-0.5}$

where $\varepsilon_{r}$ is the dielectric constant of the substrate, $p$ is the width of the monopole, and $h$ is the thickness of the substrate. The radiating elements of the antenna are designed using a lossy material (cooper) with a standard thickness of $0.035 \mathrm{~mm}$ and are printed on top of an FR-4 substrate $\left(\tan \delta=0.02\right.$ and $\varepsilon_{r}=4.4$, thickness $=1.6 \mathrm{~mm}$ ). To ensure accurate simulation, a sub-miniature version A (SMA) connector model was used to estimate the effect of the connector on antenna performance during actual measurements. The monopole (Antenna-1; dimensions of $15 \mathrm{~mm} \times 20$ $\mathrm{mm}$ ) resonates at around $6 \mathrm{GHz}$. A quarter-wavelength-sized inverted-L-shaped stub (Antenna-2) was attached to the monopole for additional resonance at $2.4 \mathrm{GHz}$. To accommodate the longer stub, the substrate size was increased to $21 \mathrm{~mm} \times 20 \mathrm{~mm}$. To keep the antenna compact, the stub was folded and a portion was printed on the back of the substrate, connected to the main stub via a metallic pin (Antenna-3). Then, additional (similarly optimized) inverted-L shaped stubs were added (Antennas-4 and-5) to generate resonance at 2.4/3.5/6 GHz and 2.4/3.5/5.5/6 GHz, respectively. The design evolution is shown in Fig. 2. The stub positions and dimensions were carefully chosen. With the exception of Antenna-2, all antennas are $15 \mathrm{~mm} \times 20 \mathrm{~mm}$ in size.

The reflection coefficient $\left(\left|S_{11}\right|\right.$ values) of each antenna involved in the final design is also plotted for a clear understanding of the design procedure. Fig. 3a shows the $\left|\mathrm{S}_{11}\right|$ plots of the initial design, i.e., of the triangular monopole alone (Antenna-1) and the monopole with straight (Antenna-2) and folded (Antenna-3) inverted-L-shaped stubs. The bandwidth of Antenna-1 ranges from 5.5 to $6.5 \mathrm{GHz}$ because it is partially grounded [31]. Antennas-2 and-3 exhibit very similar performance because the stub sizes are the same, providing resonance at $2.4 \mathrm{GHz}$ (range: 2.39 $2.51 \mathrm{GHz}$ ) as well as $6 \mathrm{GHz}$. The stub length was optimized for resonance at $2.4 \mathrm{GHz}$. According 
to the fundamental monopole antenna theory, the length of the entire stub should be about a quarter-wavelength at the resonance frequency, i.e., $31.2 \mathrm{~mm}$ at $2.4 \mathrm{GHz}$. The total stub length of Antenna-3 is $p+l_{1}+w_{1}+h+w_{4}=7+6+13+1.6+5.4=33 \mathrm{~mm}$, which is very close to the theoretical requirement. In Antenna-4, a quarter-wavelength stub is added to the initial stub. This adds $p+l p_{2}+w_{2}=7+4+9.8=20.8 \mathrm{~mm}$ to Antenna-3, for additional resonance at 3.5 $\mathrm{GHz}$ (Fig. 3b). Thus, the stubs allow current to follow several paths, explaining the multiband behavior [32].

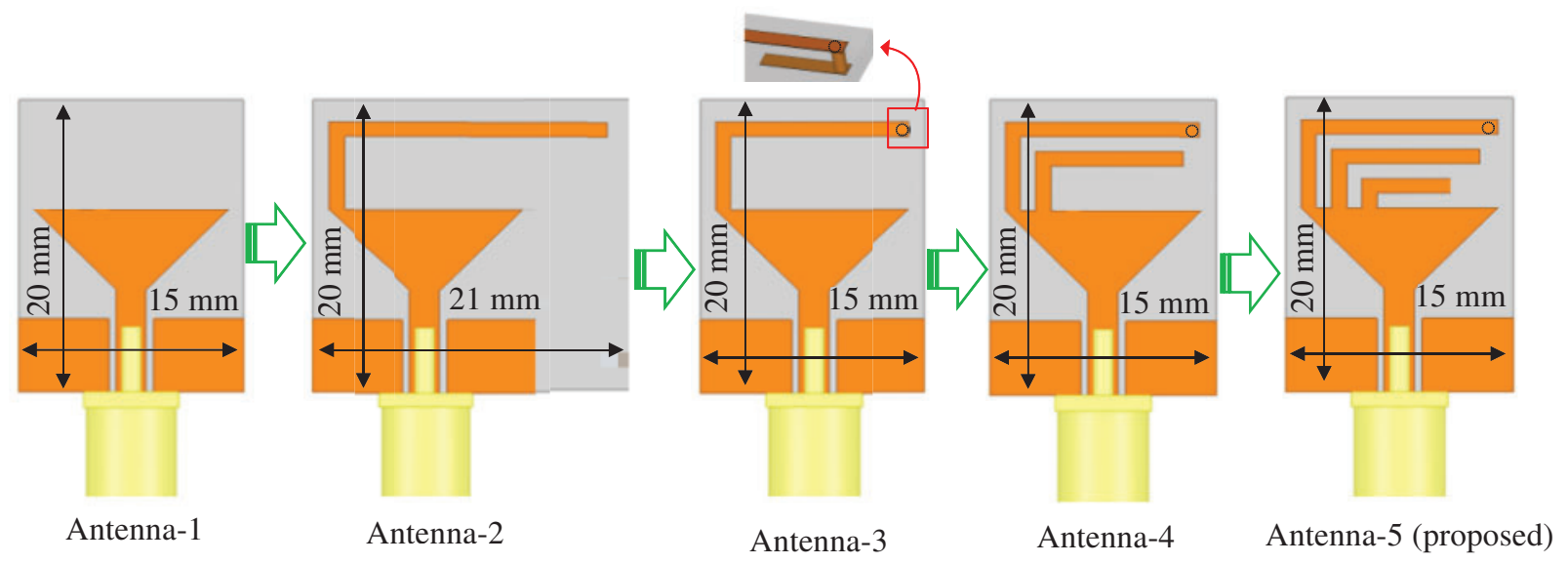

Figure 2: Design evolution of the proposed tri-band antenna

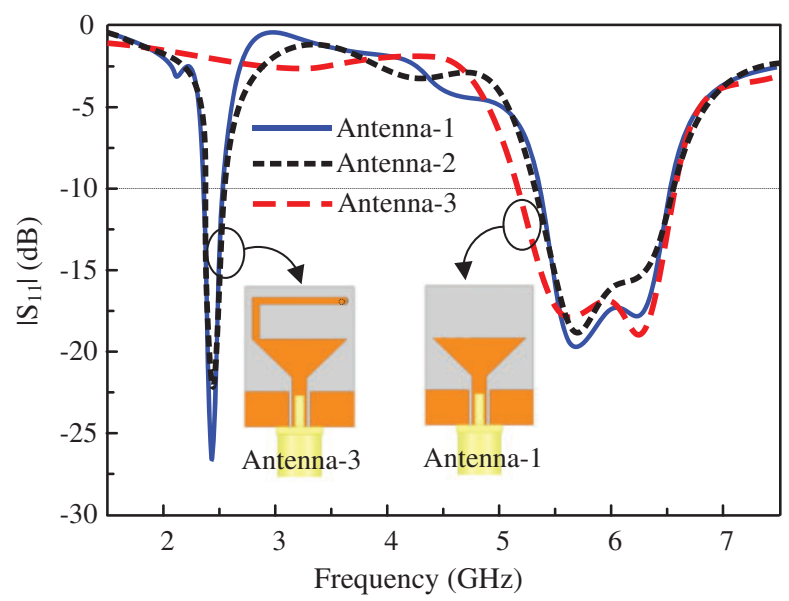

(a)

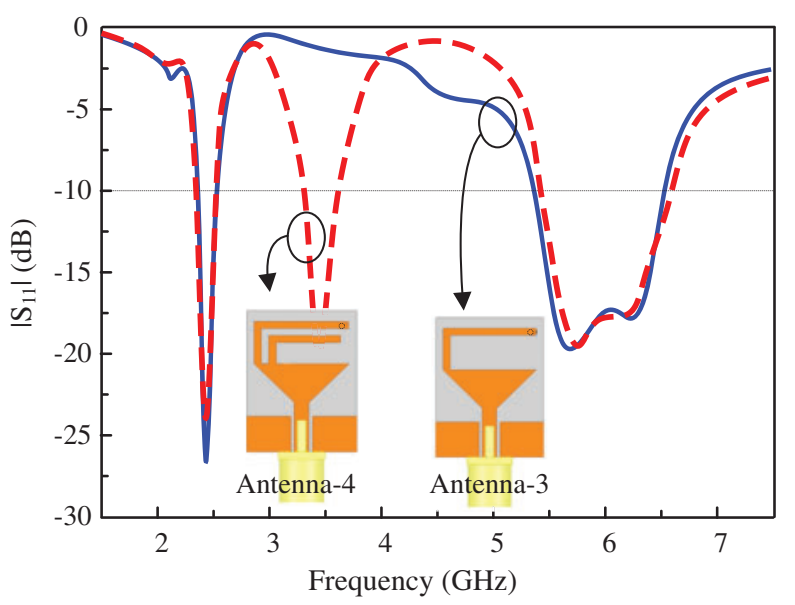

(b)

Figure 3: $\left|\mathrm{S}_{11}\right|$ characteristics: comparison of (a) Antennas-1,-2, and-3, and of (b) Antennas-3 and-4

Similarly, another inverted-L stub was added to generate an additional band at $5 \mathrm{GHz}$ [Antenna-5 (proposed antenna) in Fig. 4]. The 5 and $6 \mathrm{GHz}$ bands deliberately overlap to provide the required ultrawide bandwidth (4.6-6.4 GHz) for the WLAN band. 


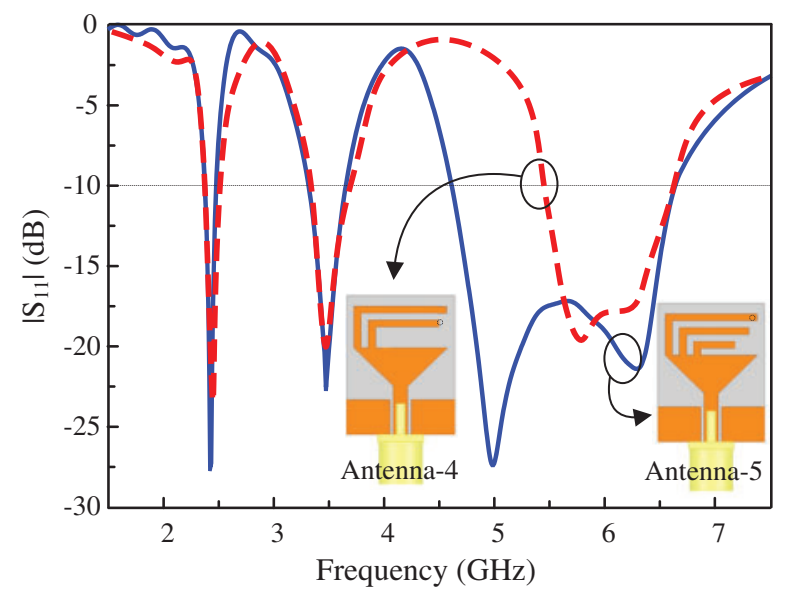

Figure 4: $\left|\mathrm{S}_{11}\right|$ characteristics of the Antenna-4 and-5 (proposed antenna)

Importantly, we can tune the operating frequency by varying stub length. Resonance shifts to low frequencies when stub length is increased. Operating frequency can be increased according to user requirements by reducing the stub length. This can be understood by examining the $\left|\mathrm{S}_{11}\right|$ characteristics of the final design with various values of $w_{4}$ and $w_{2}$ (Fig. 5).
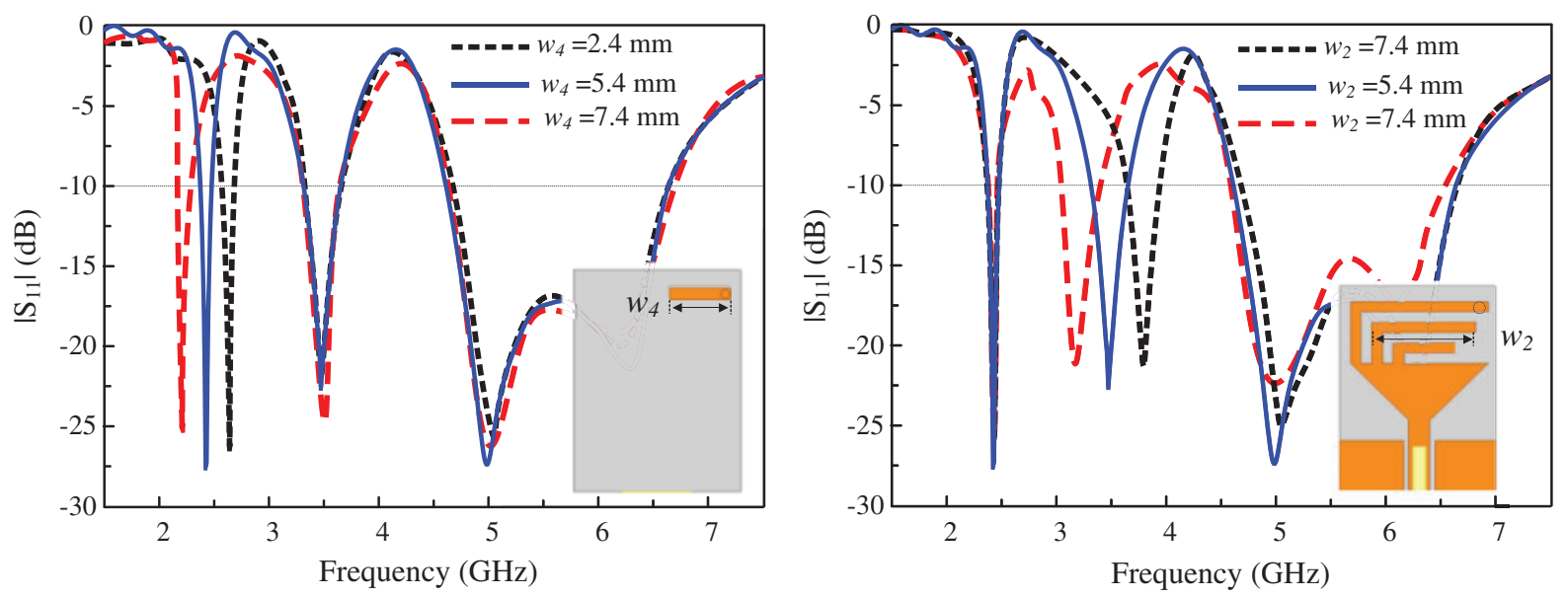

Figure 5: $\left|\mathrm{S}_{11}\right|$ characteristics of the tri-band antenna at various values of (a) $w_{4}$ and (b) $w_{2}$

To explain the radiation mechanism, the surface current densities at the resonance frequencies are plotted in Fig. 6. At $2.4 \mathrm{GHz}$, the current is mainly in stub-1, but is distributed around stub-2 at $3.5 \mathrm{GHz}$. As predicted, the current is in stub-3 at $5 \mathrm{GHz}$. Thus, the compact antenna operating on demand at 2.4, 3.5, and 5.5 GHz enables RFID, Bluetooth, WiMAX, and WLAN band applications. 

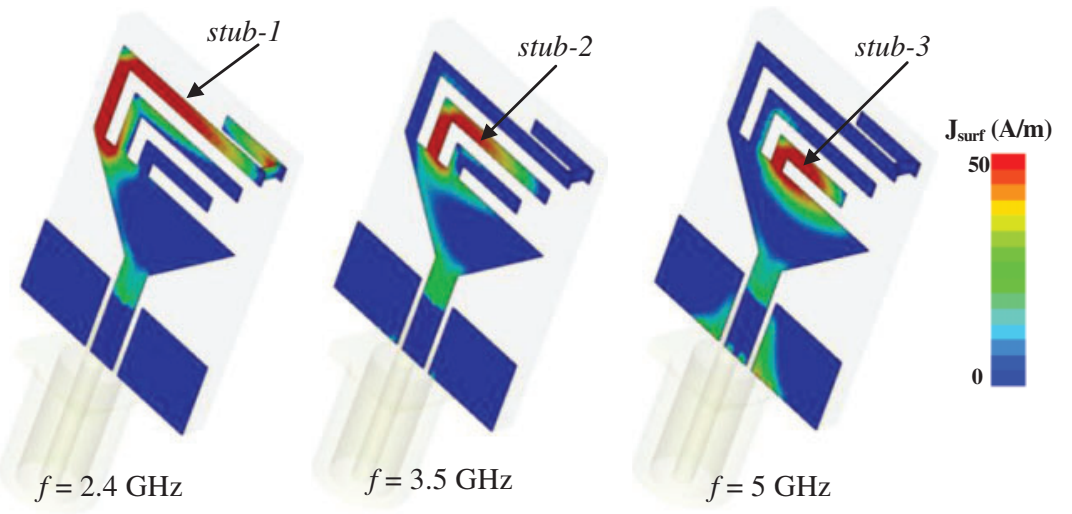

Figure 6: $\left|\mathrm{S}_{11}\right|$ Surface current distributions of the antenna at various resonance frequencies

\section{Results and Discussion}

We used standard photolithography to fabricate a prototype of the antenna and measured its performance (Fig. 7). The antenna is very compact and can be easily embedded in small devices, such as USB dongles. The $\left|\mathrm{S}_{11}\right|$ values were measured using an E5071C network analyzer (Agilent, Santa Clara, CA, USA), and far-field data were obtained with the antenna in an anechoic chamber.
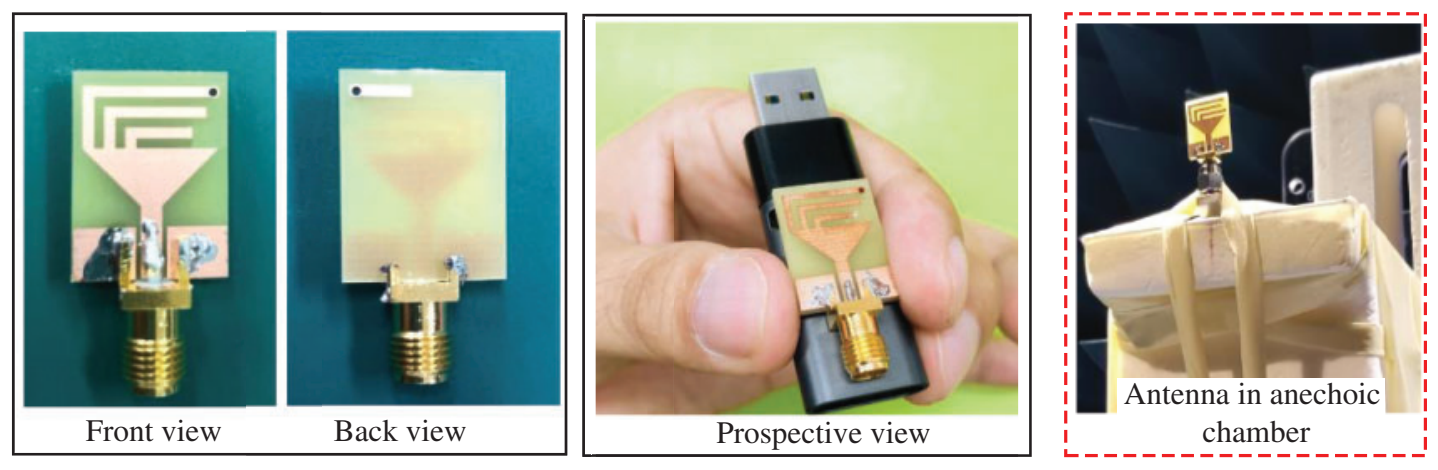

Figure 7: Photographs of the fabricated prototype

Fig. 8 shows the simulated and measured $\left|S_{11}\right|$ plots. The measurements are in good agreement with the simulations. The antenna resonates at three bands: 2.4 (2.38-2.51), 3.5 (3.34-3.71), and 5.5 (4.6-6.4) GHz, and impedance matching is good.

The simulated and measured gains plotted as well as the simulated radiation efficiency as a function of frequency, are shown in Fig. 9. The antenna exhibits a minimum measured gain of $1.8 \mathrm{dBi}$ at the lowest resonance $(2.4 \mathrm{GHz}), 2.9 \mathrm{dBi}$ in the middle band $(3.5 \mathrm{GHz})$, and $4 \mathrm{dBi}$ in the upper band $(5.5 \mathrm{GHz})$. In contrast, the gain decreases to $-3.9 \mathrm{dBi}$ in the stop-bands, validating gain suppression at out-of-band frequencies. In general, the gain increases in the pass-band with the increasing frequency due to the increased effective size of the antenna $[33,34]$. Similarly, the 
antenna shows a high radiation efficiency (up to $88 \%$ ) at resonating bands, while it is reduced to $40 \%$ at out-of-band frequencies.

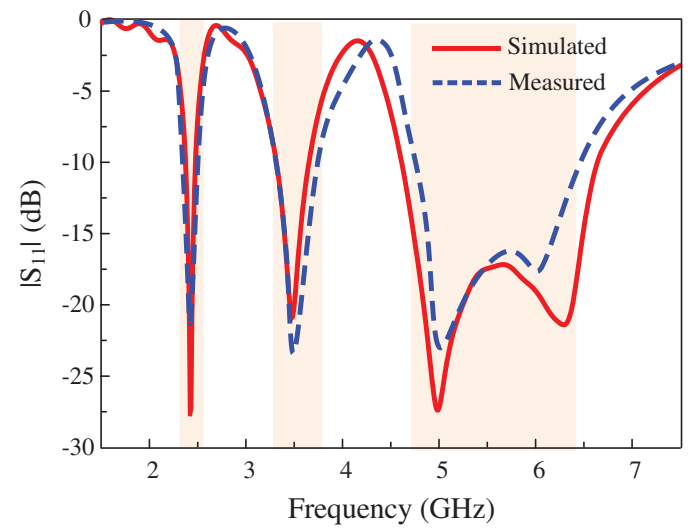

Figure 8: Simulated and measured $\left|\mathrm{S}_{11}\right|$ values of the proposed antenna

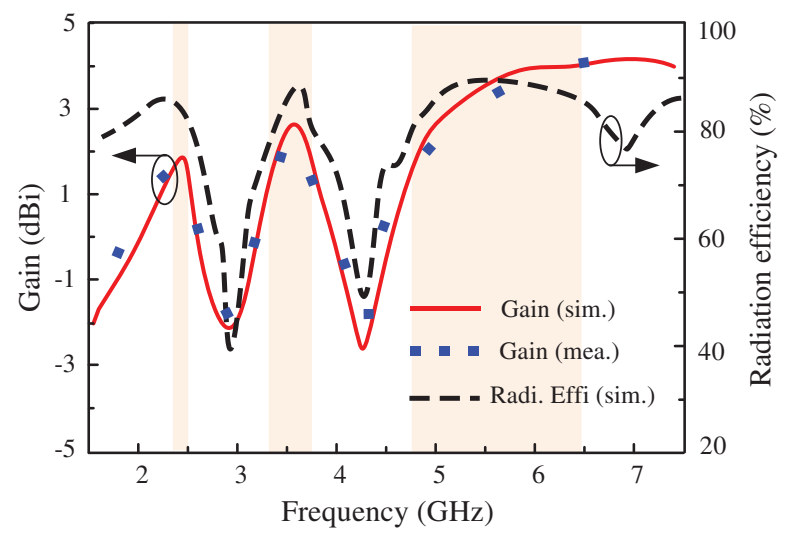

Figure 9: Gain and radiation efficiency of the proposed antenna

The radiation patterns at 2.4, 3.5, 5, and $6 \mathrm{GHz}$ are shown in Fig. 10. The antenna exhibits omnidirectional radiation in the $H$-plane and bidirectional radiation in the $E$-plane. These patterns are stable at all frequencies; this is a particular strength of the design.

\section{Performance Comparison}

The performance of our antenna, in terms of size, operating bands, and average gain, is compared to those of state-of-the-art tri-band antennas [21-30] in Tab. 1. Our antenna outperforms the others in terms of size, gain, and radiation stability. The antennas in [22,27,30] have higher gains but are large in size. Our antenna is simple, and the operating frequency bands can be tuned as required. The small size and good radiation characteristics reflect the careful design of inverted-L stubs on a triangular monopole. 

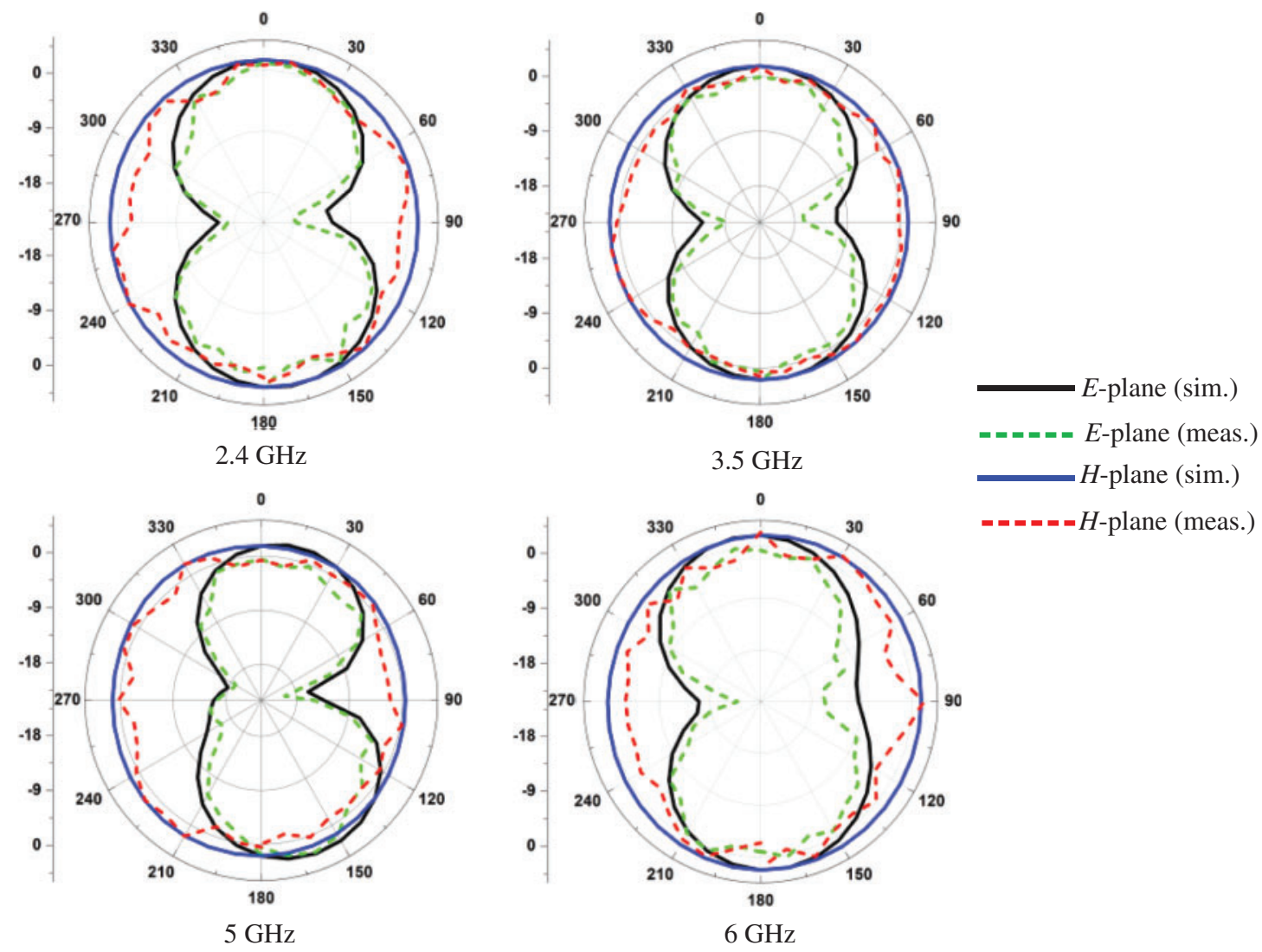

Figure 10: Simulated and measured radiation patterns at different resonating frequencies

Table 1: Performance comparison of the antenna with other tri-band antennas

\begin{tabular}{llll}
\hline Antennas & Overall size $\left(\mathrm{mm}^{3}\right)$ & Operating bands $(\mathrm{GHz})$ & Average gain $(\mathrm{dBi})$ \\
\hline$[21]$ & $25.8 \times 20 \times 1.6$ & $1.8,3.5,5.5$ & 1.93 \\
{$[22]$} & $27.5 \times 20 \times 1.5$ & $2.44,3.5,5.5$ & 3.93 \\
{$[23]$} & $26.0 \times 16 \times 1.6$ & $2.3,3.5,5.5$ & 2.3 \\
{$[24]$} & $32 \times 12 \times 1.6$ & $2.5,3.5,5.5$ & 1.67 \\
{$[25]$} & $22 \times 16.0 \times 1.6$ & $2.4,5.2,8.2$ & 1.29 \\
{$[26]$} & $27 \times 25 \times 1.6$ & $2.4,3.5,5.5$ & 2.46 \\
{$[27]$} & $125 \times 108 \times 1.5$ & $1.7,2.3,3.5$ & 4.22 \\
{$[28]$} & $32 \times 12 \times 1.5$ & $2.4,3.5,5.8$ & 2.9 \\
{$[29]$} & $40 \times 36 \times 1.52$ & $2.5,3.5,5.5$ & 2.36 \\
{$[30]$} & $40 \times 10 \times 1.52$ & $2.45,3.5,5.5$ & 2.95 \\
This work & $\mathbf{2 0} \times \mathbf{1 5} \times \mathbf{1 . 6}$ & $\mathbf{2 . 4 , 3 . 5 , 5 . 5}$ & $\mathbf{2 . 9}$ \\
\hline
\end{tabular}

\section{Conclusion}

We designed and built a tri-band monopole antenna based on inverted-L shaped stubs. Multiband behavior was achieved by connecting stubs of various lengths to the upper side of a 
triangular monopole. The antenna was fabricated on a low-cost, commercial 1.6-mm-thick FR-4 substrate. The measurements validated the computed results. The antenna is small $(20 \times 15 \times$ $1.6 \mathrm{~mm}^{3}$ ), and exhibits good impedance matching and gain/radiation patterns. The bandwidths allow operation at 2.4 (2.37-2.51), 3.5 (3.34-3.71), and 5.5 (4.6-6.4) GHz.

Funding Statement: This work was supported by the ICT R\&D program of MSIT/IITP, [20190-00102, A Study on Public Health and Safety in a Complex EMF Environment]. This work was also supported by the National Radio ResearchAgency, [Rapid measurement system for new technologyantenna].

Conflicts of Interest: The authors declare that they have no conflicts of interest to report regarding the present study.

\section{References}

[1] E. H. Lim and K. W. Leung, "Compact multifunctional antennas in microwave wireless systems," in Compact Multifunctional Antennas for Wireless Systems. Hoboken, NJ, USA: John Wiley \& Sons, pp. 128, 2012.

[2] D. K. Naji, "Miniature slotted semi-circular dual-band antenna for WiMAX and WLAN applications," Journal of Electromagnetic Engineering and Science, vol. 20, no. 2, pp. 115-124, 2020.

[3] T. Ali, M. M. Khaleeq and R. C. Biradar, "A multi-band reconfigurable slot antenna for wireless applications," AEU-International Journal of Electronics and Communications, vol. 84, no. 2, pp. 273-280, 2018.

[4] S.-H. Lee and Y. Sung, "Multi-band antenna for wireless USB dongle applications," IEEE Antennas and Wireless Propagation Letters, vol. 10, pp. 25-28, 2011.

[5] I. Ahmad, H. Dildar, W. U. Khan, S. Ullah, S. Ullah et al., "Frequency reconfigurable antenna for multi standard wireless and mobile communication systems," Computers, Materials \& Continua, vol. 68, no. 2, pp. 2563-2578, 2021.

[6] C. Y. Pan, C. H. Huang and T. S. Horng, "A new printed G-shaped monopole antenna for dual-band WLAN applications," Microwave Optical Technology Letters, vol. 45, no. 4, pp. 295-297, 2005.

[7] A. Haider, T. Khan, M. Rahman, B. M. Lee and H. S. Kim, "Quintuple band antenna for wireless applications with small form factor," Computers, Materials \& Continua, vol. 66, no. 3, pp. 2241-2251, 2021.

[8] H. B. Kim, K. C. Hwang and Y. B. Park, "Compact stub-loaded meander line antenna for wireless USB dongle devices," Microwave and Optical Technology Letters, vol. 52, no. 10, pp. 2279-2282, 2010.

[9] S. L. Gunamony, J. B. Gnanadhas and D. E. Lawrence, "Design and investigation of a miniaturized single-layer ACS-fed dual band antenna for LTE and 5G applications," Journal of Electromagnetic Engineering and Science, vol. 20, no. 3, pp. 213-220, 2020.

[10] W. P. Lin, D. H. Yang and Z. D. Lin, "Compact dual-band planar inverted E-shaped antenna using defected ground structure," International Journal of Antennas \& Propagation, vol. 2014, no. 8, pp. 937423, 2014.

[11] R. Patel, A. Desai and T. Upadhyaya, "An electrically small antenna using defected ground structure for RFID, GPS and IEEE $802.11 \mathrm{a} / \mathrm{b} / \mathrm{g} / \mathrm{s}$ applications," Progress in Electromagnetic Research Letters, vol. 75, pp. 75-81, 2018.

[12] J. Singh, R. Stephan and M. A. Hein, "Low-profile penta-band automotive patch antenna using horizontal stacking and corner feeding," IEEE Access, vol. 7, pp. 74198-74205, 2019.

[13] M. P. Raju, D. P. Kishore and B. T. P. Madhav, "CPW fed T-shaped wearable antenna for ISM Band, Wi-Fi, WiMAX, WLAN and fixed satellite service applications," Journal of Electromagnetic Engineering and Science, vol. 19, no. 2, pp. 140-146, 2019.

[14] J. H. Lu and B.-J. Huang, "Planar multi-band monopole antenna with L-shaped parasitic strip for WiMAX application,” Electronic Letters, vol. 47, no. 12, pp. 671-672, 2010. 
[15] S. Khan, X. C. Ren, H. Ali, C. Tanougast, A. Rauf et al., "Reconfigurable compact wide-band circularly polarised dielectric resonator antenna for wireless applications," Computers, Materials \& Continua, vol. 68 , no. 2, pp. 2095-2109, 2021.

[16] A. Ambika, C. Tharini and M. T. Ali, "Novel D SRR-based dual band antenna for WiMAX/C applications," Microwave and Optical Technology Letters, vol. 61, no. 2, pp. 309-315, 2019.

[17] Y. Xie, F. Chen and J. Qian, "Design of integrated duplexing and multi-band filtering slot antennas," IEEE Access, vol. 8, pp. 126119-126126, 2020.

[18] R. K. Saraswat and M. Kumar, "A metamaterial hepta-band antenna for wireless applications with specific absorption rate reduction," International Journal of RF and Microwave Computer-Aided Engineering, vol. 29, no. 10, pp. 21824, 2019.

[19] D. A. Sehrai, F. Muhammad, S. H. Kiani, Z. H. Abbas, M. Tufail et al., "Gain-enhanced metamaterial based antenna for 5G communication standards," Computers, Materials \& Continua, vol. 64, no. 3, pp. 1587-1599, 2020.

[20] R. Sahoo and D. Vakula, "Compact metamaterial inspired conformal dual-band antenna loaded with meander lines and fractal shaped inductor for Wi-Fi and WiMAX applications," IET Microwaves, Antennas \& Propagation, vol. 13, no. 13, pp. 2349-2359, 2019.

[21] C. V. A. Kumar, B. Paul and P. Mohanan, "Compact triband dual F-shaped antenna for DCS/WiMAX /WLAN applications," Progress In Electromagnetics Research Letters, vol. 78, pp. 97-104, 2018.

[22] H. Ahmad, W. Zaman, S. Bashir and M. Rahman, "Compact triband slotted printed monopole antenna for WLAN and WiMAX applications," International Journal of RF and Microwave ComputerAided Engineering, vol. 30, no. 1, pp. 21986, 2020.

[23] P. V. Naidu, A. Kumar and R. Rengasamy, "Uniplanar ACS fed multi-band high-gain antenna with extended rectangular strips for portable system applications," International Journal of RF and Microwave Computer-Aided Engineering, vol. 29, no. 10, pp. 21870, 2019.

[24] L. Kang, H. Wang, X. H. Wang and X. Shi, "Compact ACS-fed monopole antenna with rectangular SRRs for tri-band operation,” Electronics Letters, vol. 50, no. 16, pp. 1112-1114, 2014.

[25] R. Rajkumar and U. K. Kommuri, "A compact ACS-fed mirrored L-shaped monopole antenna with SRR loaded for multi-band operation," Progress in Electromagnetics Research C, vol. 64, pp. 159-167, 2016.

[26] V. Rajeshkumar and S. Raghavan, "A compact metamaterial inspired triple band antenna for reconfigurable WLAN/WiMAX applications," AEU-International Journal of Electronics and Communications, vol. 69, no. 1, pp. 274-280, 2015.

[27] J. Park, M. Jeong, N. Hussain, S. Rhee, P. Kim et al., "Design and fabrication of triple-band folded dipole antenna for GPS/DCS/WLAN/WiMAX applications," Microwave and Optical Technology Letters, vol. 61 , no. 5, pp. 1328-1332, 2019.

[28] K. K. Naik, "Asymmetric CPW-fed SRR patch antenna for WLAN/WiMAX applications," $A E U$ International Journal of Electronics and Communications, vol. 93, pp. 103-108, 2018.

[29] L. Chouti, I. Messaoudene, T. A. Denidni and A. Benghalia, "Triple-band CPW-fed monopole antenna for WLAN/WiMAX applications," Progress in Electromagnetics Research Letters, vol. 69, pp. 1-7, 2017.

[30] W. Y. Chiang, C. H. Ku, C. A. Chen, L. Y. Wang, P. A. R. Abu et al., "A power-efficient multi-band planar USB dongle antenna for wireless sensor networks," Sensors, vol. 19, no. 11, pp. 2568, 2019.

[31] N. Hussain, M. Jeong, J. Park, S. Rhee, P. Kim et al., "A compact size 2.9-23.5 GHz microstrip patch antenna with WLAN band-rejection," Microwave and Optical Technology Letters, vol. 61, no. 5, pp. 1307-1313, 2019.

[32] S. H. Kiani, A. Altaf, M. Abdullah, F. Muhammad, N. Shoaib et al., "Eight element side edged framed MIMO antenna array for future 5G smart phones," Micromachines, vol. 11, no. 11, pp. 956, 2020. 
[33] A. Zaidi, W. A. Awan, N. Hussain and A. Baghdad, "A wide and tri-band flexible antennas with independently controllable notch bands for sub-6-GHz communication system," Radioengineering, vol. 29, no. 1 , pp. 44-51, 2020.

[34] M. U. Hassan, F. Arshad, S. I. Naqvi, Y. Amin and H. Tenhunen, "A compact flexible and frequency reconfigurable antenna for quintuple applications," Radioengineering, vol. 26, no. 3, pp. 655-661, 2017. 